Open Scientist Handbook • OSH

\title{
The Zero-Asshole Zone Goal
}

\section{Bruce R. Caron}

Published on: Mar 10, 2021

DOI: $10.21428 / 8 b b b 7 f 85.8 e 4416 \mathrm{~d} 1$

License: Creative Commons Attribution 4.0 International License (CC-BY 4.0). 


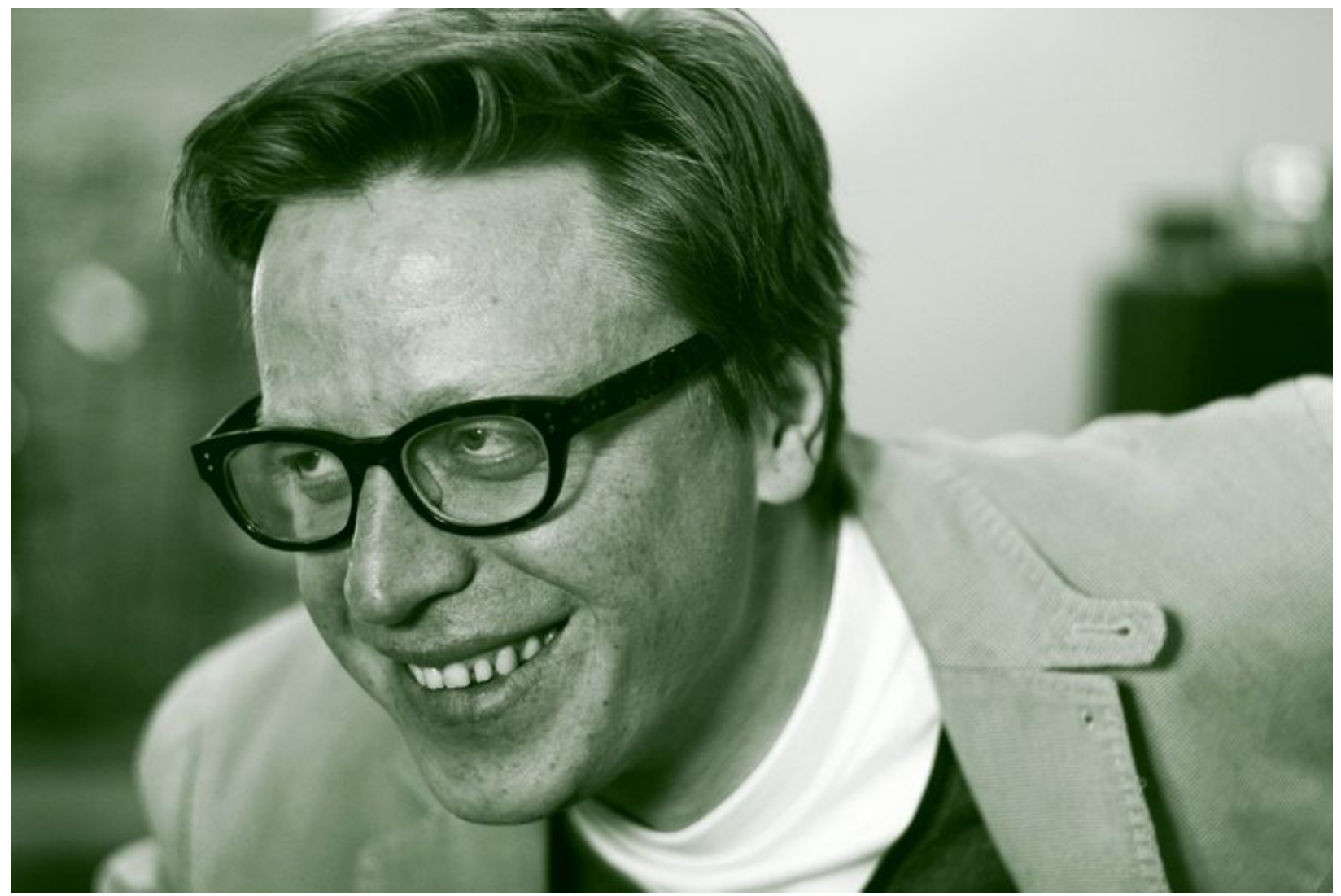

All it takes is one asshole to ruin you life. Photo Credit: Igor Pavlov on Flickr CC licensed

"First: the asshole helps himself to special privileges in cooperative life; second: he does this out of an intrenched sense of entitlement; third: he is immunized against the complaints of other people." Aaron James: Assholes: a Theory... the intro video (2012) < $\underline{\text { https://youtu.be/d2y-pt0makw> }}$

"An asshole is someone who leaves us feeling demeaned, de-energized, disrespected, and/or oppressed. In other words, someone who makes you feel like dirt” (Robert Sutton 2019; Accessed April 9, 2019).

\section{Your organization can make this happen}

Depending on who you talk to, the academy's asshole problem is either extremely dire, vastly complicated, or both. Very few people would say it doesn't exist. The "complicated" version tries to balance assholish behaviors with some idea that the 
pursuit of new knowledge in a hyper-competitive environment requires a intellectual with an enhanced sense of self-confidence, an enormous ego, a thick skin, and relentless drive. Only a complete narcissist can out-compete all the other assholes in the struggle for resources and credit. Colleagues who hang around this social-blackhole personality hope to ride along in the car of his success (i.e., "He may well be an asshole, but he's our asshole"):

"The traits associated with narcissism explain why some people have an innate ability to dominate the scene. This includes the good serious face that implicitly tells their entourage that their research is important but also their willingness to use resources without any scruples or any sense of a possible cost for the community as a whole. This provides advantages in a system that monitors production and not productivity. We can understand why these innate leaders have supporters that praise their qualities - because of their fast-track access to resources that are usually difficult to get" (Lemaitre 2015).

This "nice scientists finish last" mind-set serves to demonstrate why open science, with fierce equality and demand sharing, is an important, and urgent, remedy for the academy. The "cost" to the community-and to your own team, lab, department, or school-of even one real asshole is greater than you might at first guess. Assholes breed more assholes as they chase away nice, clever people. "Ultimately we are all diminished when clever people walk away from academia. So what can we do? It's tempting to point the finger at senior academics for creating a poor workplace culture, but I've experienced this behaviour from people at all levels of the academic hierarchy. We need to work together to break the circle of nastiness" (emphasis in the original) (Mewburn 2015; Accessed April 9, 2019).

\section{You can argue ideas without being an asshole}

It is really important here to understand that arguments over ideas are not intrinsically assholish events. As we will see below, assholes demean other individuals; their behavior is aimed at people. They will also be abrasive and demeaning in the manner in which they defend their ideas. We've all witnessed this in conferences and seminars. Entire paragraphs of meeting "code of conduct" rules are meant to counteract this kind of behavior. Sutton offers this: “enforcing a no asshole rule doesn't mean turning your organization into a paradise for conflict-averse wimps. The best groups and organizations-especially the most creative ones-are places where people know how to fight" (Sutton 2007). 
Another complication the academy has is this: assholes with tenure. Sutton has no clear answer for this problem: "'I'm with all these colleagues that are all tenured, and Stanford has no mandatory retirement,' he points out. 'So when I'm with an asshole, all I can do is hope'" (Sutton 2017; Accessed 4/9/2019; emphasis in the original).

"Science advances one funeral at a time;" Max Planck (1932/2015) had other, grand theoretical, reasons to say this. It also applies to assholes with tenure. So the best thing to do is: never hire an asshole in the first place. This is the essential message of the No Asshole Rule. No matter how much of an academic star she/he might be, adding him/her to your faculty is a huge mistake, even more so when they show up already with tenure.

In a corporate environment, you can just ask a high-powered jerk employee to go be a jerk in some other corporation. CEO coaches offer a simple principle: "'genuine collaboration and accountability for our own actions are non-negotiable if you plan on succeeding in this place'. ... Get this right [as a CEO], and you will set yourself up with a culture that delivers far greater and more consistent long term success than the short term spikes delivered by a Jerk!” (ㅍrancis 2017; Accessed April 9, 2019).

Assholes in positions of power in your organization can be sidetracked as much as possible, isolated and ignored as circumstances allow. Graduate students can be warned away, administrators can be informed, and professional associations-where these assholes are eager to get into leadership positions-can be immunized through active word-of-mouth. Remember that a single asshole can impact your organization for years.

In The Problem with Assholes, Elizabeth Cullen Dunn announced that "Anthropology has an asshole problem." She notes, "[a]ssholery is contagious. Once people see an asshole being an asshole and winning, actually gaining power and prestige by being an obnoxious self-interested bully, it creates a huge incentive for other people to emulate that behavior. Assholery has ripple effects as it spreads in the form of disciplinary norms that not only enable, but hyper-value nasty, elitist, demeaning behavior" (Dunn 2018; Accessed April 9, 2019). Anthropology is not alone. In a 2018 report, the National Academies note: "In a survey conducted by the University of Texas System..., about 20 percent of female science students (undergraduate and graduate) experienced sexual harassment from faculty or staff, while more than a quarter of female engineering students and greater than 40 percent of medical students experienced sexual harassment from faculty or staff" (NAS 2018). The asshole problem is acute across the academy. 


\section{Situational assholes}

Sutton (2018 and 2007) notes that, on occasion, anyone can act assholishly. These "temporary assholes" are not the real problem. They tend to want to repair their lapses of civility, and to feel bad about their own behavior. The real problem comes from "authentic assholes." Authentic assholes display durable personality issues, and are also more likely to engage in an "exploitative sexual style" (Jones and Figueredo 2013) that seeks instrumental sex with multiple partners; a trait that powers workplace harassment.

There is also a subset of assholes in the academy who are "accidental assholes" (Sepah 2017; Accessed April 9, 2019). These are nerdish individuals who are, for example, on the autism spectrum, and who do not have the social skills to always act appropriately. They may do randomly assholish things, or they may simply copy the bad behaviors they find around them. Accidental assholes are still jerks. And being on the spectrum is no excuse. "It's a conscious choice, no matter how much lead-in, to become like that," Brandon Weaver (2019; Accessed November 10, 2019) explains.

Not all assholes are born that way: lots of them are nurtured into bad behaviors on the job. The current, toxic academic culture can turn a temporary asshole into an chronic bad actor, a kind of "opportune asshole;" (or, in evolutionary culture terms, an "adaptive asshole"): someone who believes that bad behavior is expected of them and rewarded by their peers. They are happy to oblige.

This may be why so many precincts of the academy seem to be swarming with assholes (jerks, bad-actors, etc.). When you add the opportune- and temporary-assholes to the authentic ones, the numbers and their bad effects really add up. Sutton addressed this situation in an article in the Harvard Business Review (<https://hbr.org/2007/05/whyare-there-so-many > Accessed April 9, 2019). As the National Academies found, the most asshole-infested profession is medicine and medical school:

"A longitudinal study of nearly 3,000 medical students from 16 medical schools was just published in The British Medical Journal. Erica Frank and her colleagues at the Emory Medical School found that 42 percent of seniors reported being harassed by fellow students, professors, physicians, or patients; 84 percent reported they had been belittled and 40 percent reported being both harassed and belittled" (Sutton 2007).

So, why are we surrounded by assholes? Sutton explains: 
"The truth is that assholes breed like rabbits. Their poison quickly infects others; even worse, if you let them make hiring decisions, they will start cloning themselves. Once people believe that they can get away with treating others with contempt or, worse yet, believe they will be praised and rewarded for it, a reign of psychological terror can spread throughout your organization that is damn hard to stop" (Sutton 2007).

\section{The who is more important than the what}

The good news is that the principles of fierce equality and demand sharing are diagnostic and therapeutic in finding and neutralizing assholes. Once the opportuneassholes find that their bad behavior is no longer applauded or even acceptable, they will need to self-monitor their personal interactions. When open-science norms support public acknowledgement of the asshole problem, and offer remedies for this in departments, labs, colleges, professional associations, etc., authentic assholes will find that their toxic actions serve only to isolate and shame them (even though they may not feel this shame as shame, but convert it into anger (Brown 2012)). Over time, when new norms take hold, and new hires bring fresh non-assholic voices into the mix, your corner of the academy can regain its fundamental civility, and you and your students can again argue theories and ideas, methods and experiments, without resorting to abuse and fear.

Working in a zero-asshole environment is significantly more pleasant and productive than toiling in the psychological minefield that even one asshole can create in your department, laboratory, agency, or college. Achieving a zero-asshole status takes a principled stance and procedural follow-through. It is a worthwhile goal for you as an open science culture-change agent to pursue. "Bear in mind that negative interactions have five times the effect on mood than positive interactions-it takes a lot of good people to make up for the damage done by just a few demeaning jerks" (Sutton 2007).

\section{The asshole in the mirror}

A final thought here. Each of us is capable of astounding assholishness at any time. Most of us have experienced being on the receiving end on some occasions (in seminars, through peer review, at office hours) of abuse by those who control our academic fortunes, and use fear and humiliation in their critiques of our work, or of our capacities for research or teaching. We know how to do asshole; we've had enough training. We just need to not go there. And we need to isolate ourselves from the assholes we encounter. Sutton reminds us of this: 
"If you want to build an asshole-free environment, you've got to start by looking in the mirror. When have you been an asshole? When have you caught and spread this contagious disease? What can you do, or what have you done, to keep your inner asshole from firing away at others? The most powerful single step you can take is to...just stay away from nasty people and places. This means you must defy the temptation to work with a swarm of assholes, regardless of a job's other perks and charms. It also means that if you make this mistake, get out as fast as you can. And remember, as my student Dave Sanford taught me, that admitting you're an asshole is the first step" (Sutton 2007).

You can always take Sutton's (2007) "asshole test" to self-diagnose. Or, if you find yourself believing that you are surrounded by idiots and that you should be recognized for your real talents and elevated into a higher level of society: you are probably an asshole, or at least, a "jerk":

"Because the jerk tends to disregard the perspectives of those below him in the hierarchy, he often has little idea how he appears to them. This leads to hypocrisies. He might rage against the smallest typo in a student's or secretary's document, while producing a torrent of errors himself; it just wouldn't occur to him to apply the same standards to himself. He might insist on promptness, while always running late. He might freely reprimand other people, expecting them to take it with good grace, while any complaints directed against him earn his eternal enmity" (대witzgabel 2014; Accessed April 9, 2019).

This is a good reminder that assholes know who and what to kiss to get ahead. They may direct their assholocity at anyone/everyone lesser than them in the academic scheme, and act entirely respectful and encouraging to those above them. Your dean may not know who's an asshole, but grad-students might have a clear idea. Listen to them. They may already be organizing to minimize the impacts of faculty assholes on their future careers. At the University of North Carolina, graduate students organized "Academics taking Action" for this purpose (<https://academicstakingaction.wordpress.com/> Accessed 5/14/2019). And should you, in a moment of fatigue or stress lash out at your students, if you are a temporary asshole, then it's up to you to make them know you acted poorly and regret it.

Feeling mean today? Go ahead, be mean to your data; interrogate it ruthlessly. Be cruel to your theories. Don't look to validate them, find new ways to attack them. Be an asshole with your methodology; it's certainly not as rigorous as it could be. Then, have some more coffee and be kind and humble with your students and colleagues. 


\section{Bibliography: Open Scientist Handbook References}

